\title{
Evaluation of Degradation of PET Film by Partial Discharge Method
}

\author{
Akinori Iguchi $^{1,2}$, Hideo Hirabayashi ${ }^{1,2}$, Takahiro Hayashi ${ }^{2}$, Kazushi Yamada ${ }^{2 *}$, Hiroyuki Nishimura ${ }^{2}$ \\ ${ }^{1}$ Shinwa Sangyo Co., Ltd., Osaka, Japan; ${ }^{2}$ Kyoto Institute of Technology, Kyoto, Japan. \\ Email: *kazushi@kit.ac.jp \\ Received October $27^{\text {th }}$, 2013; revised November $30^{\text {th }}, 2013$; accepted December $23^{\text {rd }}, 2013$ \\ Copyright (C) 2014 Akinori Iguchi et al. This is an open access article distributed under the Creative Commons Attribution License, \\ which permits unrestricted use, distribution, and reproduction in any medium, provided the original work is properly cited. In accor- \\ dance of the Creative Commons Attribution License all Copyrights (c) 2014 are reserved for SCIRP and the owner of the intellectual \\ property Akinori Iguchi et al. All Copyright (C) 2014 are guarded by law and by SCIRP as a guardian.
}

\begin{abstract}
Recently, the industry and productions have been rapidly developed by the advancement of science and technology. On the other hand, the dwindling natural resources and the global warming increasingly pose a severe problem to our life in near future. Indeed, solar photovoltaic (PV) has been attractive as one of the alternative energy resource to oil. However, some problems such as the reduction of electromotive force and the degradation of back-sheet influence the properties of the long-term life of the PV panel system. In this research, we used the high- and low-molecular-weight PET film in order to evaluate the effect of molecular weight for the hydrolysis of PET under the acceleration degradation test. As results, the mechanical properties of PET film were decreased with increasing the acceleration degradation time. In addition, it was found that the dielectric breakdown strength of PET film indicated the similar tendency with the mechanical properties. Accordingly, the non-destructive analytical technique, i.e. the partial discharge measurement makes it easy to evaluate the degradation of PET film without any damage or cut out for the film.
\end{abstract}

\section{KEYWORDS}

PET Film; Back-Sheet; Partial Discharge Measurement; Degradation

\section{Introduction}

In recent years, the industry and productions have been rapidly developed by the advancement of science and technology. Many products were made mainly from polymers instead of such as metal and wood in order to reduce the weight and cost. Therefore, many research groups investigate polymer fiber [1-3], film [4-7], and composites [8-11]. On the other hand, the dwindling natural resources and the global warming increasingly pose a severe problem to our life in near future. Therefore, it is very important to facilitate the conversion from oil to other energy sources. Indeed, the solar panel electricity system, also known as solar photovoltaic (PV), has been attractive as one of the alternative energy resource to oil. The PV captures the sun's energy using photovoltaic cells. These cells don't need direct sunlight to work

"Corresponding author.
- they can still generate some electricity on a cloudy day. The cells convert the sunlight into electricity, which can be used to run household appliances and lighting. PV cells are made from layers of semi-conducting material, usually silicon and PV panels have the back-sheets consisting of PET film. When light shines on the cell, it creates an electric field across the layers. The stronger the sunshine is, the more electricity is produced. Groups of cells are mounted together in panels or modules that can be mounted on the roof. If dust, debris, snow or bird droppings are a problem, they should be removed with warm water in order to generate the high performance. However, some problems such as the reduction of electromotive force and the degradation of back-sheet influence the properties of the long-term life of the PV panel system. Therefore, it is very important to evaluate the durability of back-sheet, i.e. the properties of PET film under the acceleration degradation test. In addition, it is desi- 
red that the measurement of PET film is performed by using the non-destructive analytical technique. Accordingly, we demonstrate the partial discharge measurement technique to evaluate the degradation of PET film.

In this research, we used the different types of PET film, i.e. high- and low-molecular-weight PET film, in order to evaluate the effect of molecular weight for the hydrolysis of PET under the acceleration degradation test. The films were tested under the hot water bath and the constant temperature and humidity chamber. The difference of mechanical properties and dielectric breakdown strength were discussed on the basis of results of tensile test, partial discharge measurement, and SEM observation.

\section{Experimental}

\subsection{Materials and Acceleration Degradation Test}

As shown in Table 1, two types of PET films provided by TOYOBO Co., Ltd. (Japan) were used to evaluate the degradation properties; high-molecular-weight PET film (H-PET) and low-molecular-weight PET film (L-PET). Film thickness is $75 \mu \mathrm{m}$, respectively. These films were employed the acceleration degradation test under the hot water bath at $90^{\circ} \mathrm{C}$ and the constant temperature and humidity chamber at $85^{\circ} \mathrm{C}$, relative humidity (RH) $85 \%$. The acceleration time was set at $0,250,500,750,1000$, 1900, $2500 \mathrm{~h}$.

\subsection{Tensile Test}

The Instron universal testing machine (Instron Co. Ltd., Type: 55R4206) was used for the specimens which are the type 3 of JIS K 6251 (Rubber, vulcanized or thermoplastics-Determination of tensile stress-strain properties). The tensile speed was $10 \mathrm{~mm} / \mathrm{min}$. The average thickness and width of the specimens were $75 \mu \mathrm{m}$ and 5 $\mathrm{mm}$, respectively.

\subsection{DSC Measurement}

Differential scanning calorimetry (DSC) was carried out using a DSC PerkinElmer Pyris1 in the range from $40^{\circ} \mathrm{C}$ to $300^{\circ} \mathrm{C}$ and at a heating rate of $50^{\circ} \mathrm{C} / \mathrm{min}$ under nitrogen flux. Calibration of the temperature was made by using indium.

Table 1. Properties of PET films used in this research.

\begin{tabular}{ccc}
\hline & L-PET & H-PET \\
\hline Molecular weight $(\mathrm{Mn})$ & 7090 & 9540 \\
Film thickness $(\mu \mathrm{m})$ & 75 & 75 \\
Glass transition $\left(\mathrm{T}_{\mathrm{g}}\right)\left({ }^{\circ} \mathrm{C}\right)$ & 76.3 & 82.3 \\
\hline
\end{tabular}

\subsection{Partial Discharge Measurement}

The partial discharge testing machine was used in PET films to evaluate the dielectric breakdown property. Figure 1 shows the schematic illustration of the partial discharge testing machine. The electrodes of partial discharge were 2 parts, upper and lower. These were the following different diameter type of JIS C 2110-1 Solid electrical insulating materials-Test methods for electric strength-Part 1: Tests at power frequencies. The specimen was held between the upper and lower of electrodes and was applied to the $50 \mathrm{~Hz}$ sinusoidal voltage. The upper electrode was applied to the load of $1150 \mathrm{~g}$. The partial discharge inception voltage was over $200 \mathrm{mV}$.

\subsection{Scanning Electron Microscope (SEM) Observation}

The cross-sectional surface of PET films was observed by using SEM (JEOL Ltd., JSM-6010LA). The accelerating voltage was set at $10 \mathrm{kV}$, and the magnification was set at $\times 600$, and the spot-size of the electron beam was 50 .

\section{Results and Discussion}

\subsection{Effect of Acceleration Degradation Test for Mechanical Properties of PET Film}

Figure 2 shows the typical strength-strain curves of (a) H-PET and (b) L-PET films before and after accelerated degradation test. The tensile behaviors of PET film indicate two regions, that is, elastic region and plastic elon-

(a)

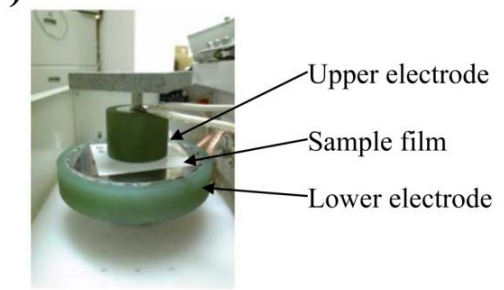

(b)

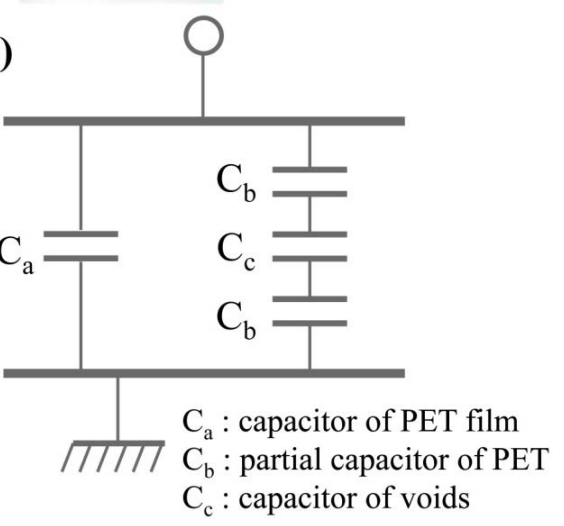

Figure 1. Photograph and schematic illustrations of the partial discharge measurement. 

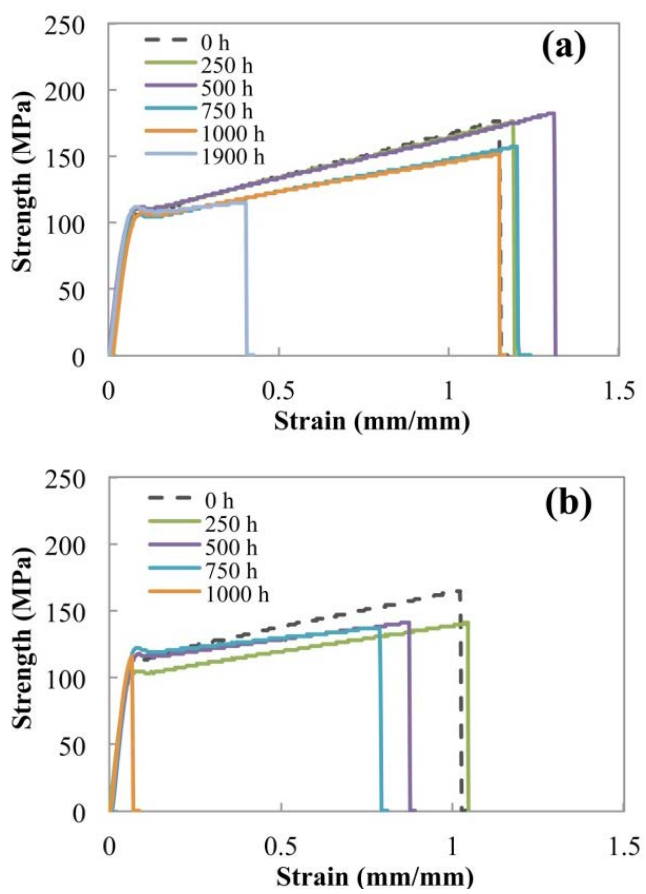

Figure 2. Typical strength-strain curves of (a) H-PET and (b) L-PET films before and after acceleration degradation test.

gation. As shown in Figure 2, the tensile property in elastic region indicated much the same tendency for each specimen. Over necking point, tensile property indicated the different tendency with the acceleration degradation time.

Figure 3 shows the tensile modulus of PET films before and after accelerated degradation test, (a) immersed in hot water at $90^{\circ} \mathrm{C}$ and (b) exposed in air chamber at $85^{\circ} \mathrm{C}$ and $\mathrm{RH}-85 \%$. For H-PET film, tensile modulus did not decrease for all conditions, whereas the tensile modulus of L-PET in hot water at $90^{\circ} \mathrm{C}$ for $1900 \mathrm{~h}$ drastically decreased because of the degradation by hydrolysis.

Figure 4 shows the tensile strength of PET films before and after accelerated degradation test. From this result, the tensile strength of all films was decreased with increasing the immersion time or exposure time in the acceleration degradation test. On the other hand, the tensile strength of L-PET indicated the lower value as compared with that of H-PET. Elongation at break of PET film before and after accelerated degradation test was shown in Figure 5. This result also indicated the same tendency with tensile modulus and tensile strength for each acceleration degradation test. From these results, it was considered that the mechanical properties of PET films were decreased with increasing the acceleration time because of the crystallization or hydrolysis of PET molecules. In addition, this declining tendency was dominantly indicated for L-PET. Therefore, it was considered that the mechanical properties of PET films were sig-
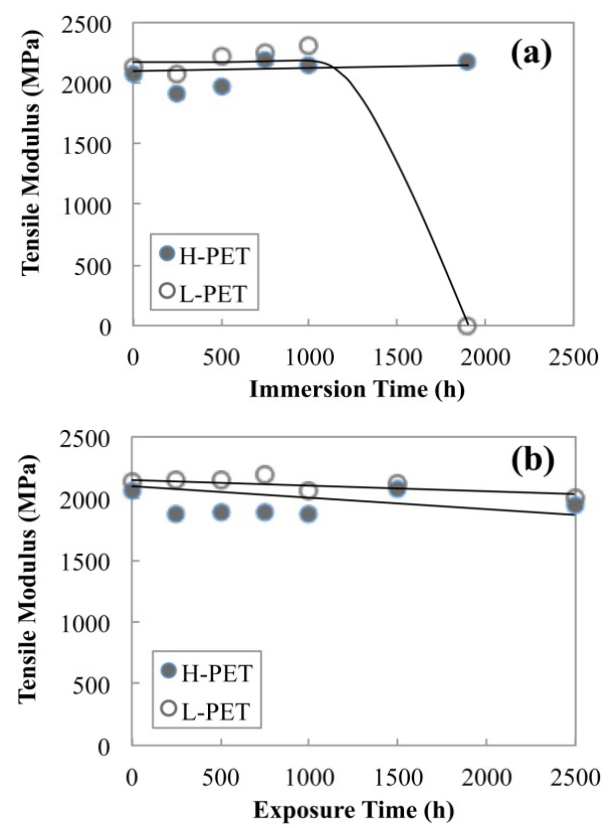

Figure 3. Tensile modulus of PET films before and after accelerated degradation test, (a) immersed in hot water at $90^{\circ} \mathrm{C}$, (b) exposed in air camber at $85^{\circ} \mathrm{C}$ and $\mathrm{RH}-85 \%$.
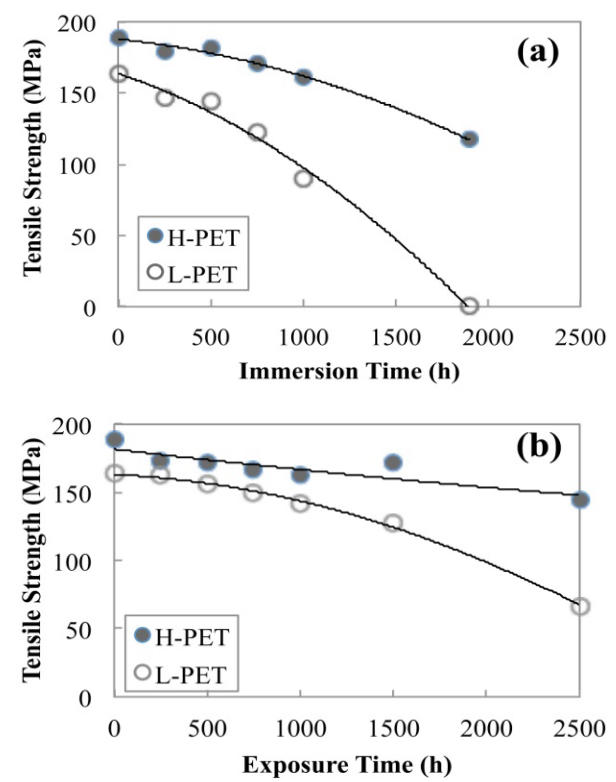

Figure 4. Tensile strength of PET films before and after accelerated degradation test, (a) immersed in hot water at $90^{\circ} \mathrm{C}$, (b) exposed in air camber at $85^{\circ} \mathrm{C}$ and $\mathrm{RH}-85 \%$.

nificantly affected by molecular weight and acceleration time.

Figure 6 shows the result of the $\Delta \mathrm{H}$ value of PET films by DSC measurement. As shown in this figure, it was found that the $\Delta \mathrm{H}$ of L-PET was higher than $\Delta \mathrm{H}$ of H-PET. It could be due to the different molecular weight of between PET films, i.e. L-PET with lower molecular weight is easy to crystallize as compared with H-PET. 

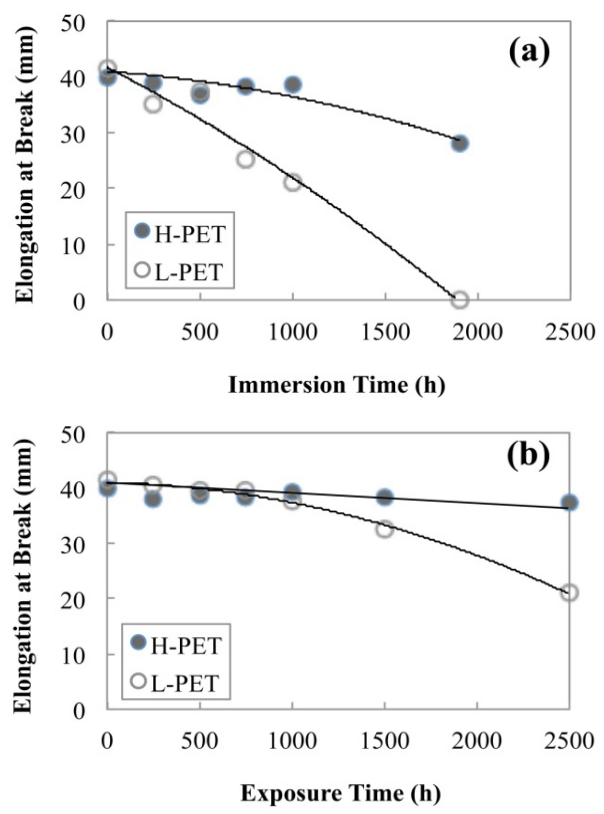

Figure 5. Elongation at break of PET films before and after accelerated degradation test, (a) immersed in hot water at $90^{\circ} \mathrm{C}$, (b) exposed in air camber at $85^{\circ} \mathrm{C}$ and $\mathrm{RH}-85 \%$.

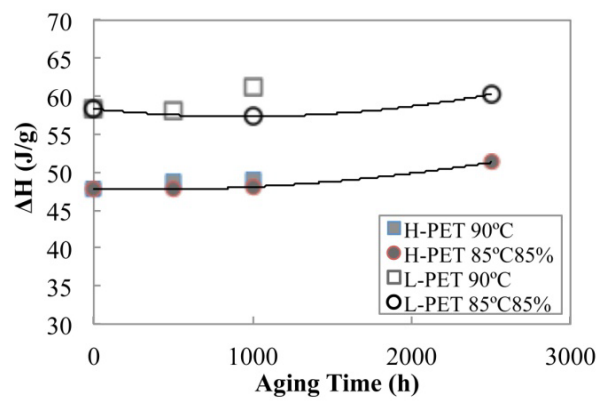

Figure 6. $\Delta \mathbf{H}$ value of PET films for aging time after accelerated test.

On the other hand, the $\Delta \mathrm{H}$ value of PET films was not indicated the drastic change with increasing the acceleration degradation time, whereas the $\Delta \mathrm{H}$ showed the almost same value for aging time. Accordingly, it is considered that the hydrolysis of PET films was promoted by the acceleration degradation test as compared with the crystallization of PET in this investigation conditions.

\subsection{Partial Discharge Measurement}

Partial discharge measurement was performed for each PET film in order to evaluate the degradation or hydrolysis of PET films as the non-destructive analytical technique. Figure 7 shows the results of partial discharge measurement for PET films immersed in hot water at $90^{\circ} \mathrm{C}$. The value of partial discharged capacity for PET was gradually increased with increasing the applied voltage for the film, although these curves have the peak and valley around $1000 \mathrm{~V}$ and $1300 \mathrm{~V}$, respectively.
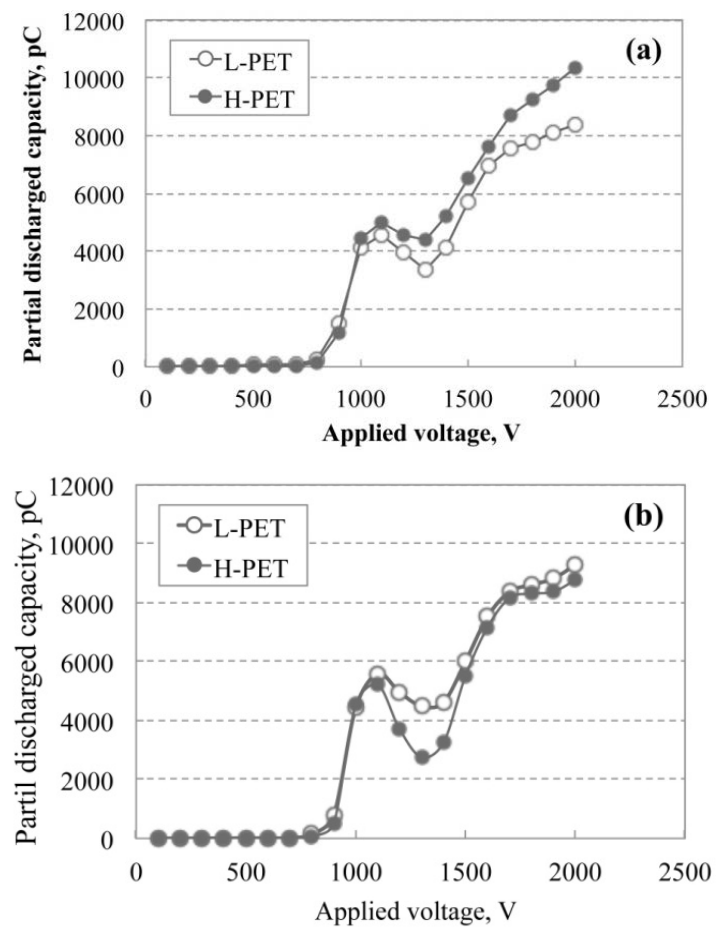

Figure 7. Partial discharged capacity for applied voltage of L-PET and H-PET films immersed in hot water at $90^{\circ} \mathrm{C}$ for (a) $1000 \mathrm{~h}$ and (b) $2500 \mathrm{~h}$.

Figure 8 shows the magnified drawing in the range from 750 to $1200 \mathrm{~V}$ for various accelerated test conditions. As shown in this figure, the initial rise point was shifted toward low voltage with increasing the acceleration degradation time. The partial discharged capacity was increased with the increasing of degradation of PET film by the acceleration test. In addition, it is considered that the capacity value is corresponding to the internal voids or cracks generated from the hydrolysis or degradation in PET films. Therefore, it is considered that the partial discharged measurement plays an important role to evaluate the degraded condition of PET films without the breaking or cut out.

On the other hand, Figure 9 shows the results of breakdown voltage for before and after accelerated degradation test. The breakdown voltage was decreased with increasing the acceleration degradation time, and the value of L-PET indicated lower than H-PET. It is considered that this difference is corresponding to the number of end groups and density of PET films. In addition, the decreasing tendency is the same with the result of partial discharged measurement. In this study, we also demonstrated the applicability of the breakdown voltage method in order to evaluate the degradation of PET films.

Figure 10 shows the cross-sectional SEM images of PET films before and after partial discharge measurement. As shown in these pictures, the difference was not observed between before and after the partial discharge 

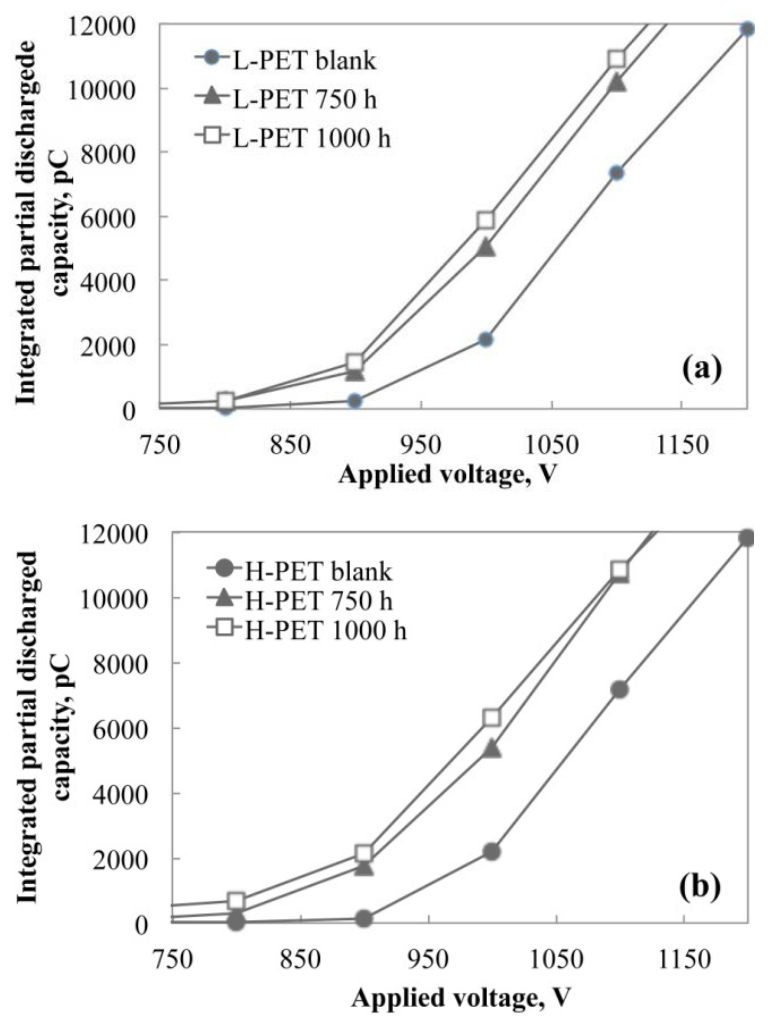

Figure 8. Integration of partial discharged capacity up to $1000 \mathrm{~V}$ for (a) L-PET and (b) H-PET films immersed in hot water at $90^{\circ} \mathrm{C}$.

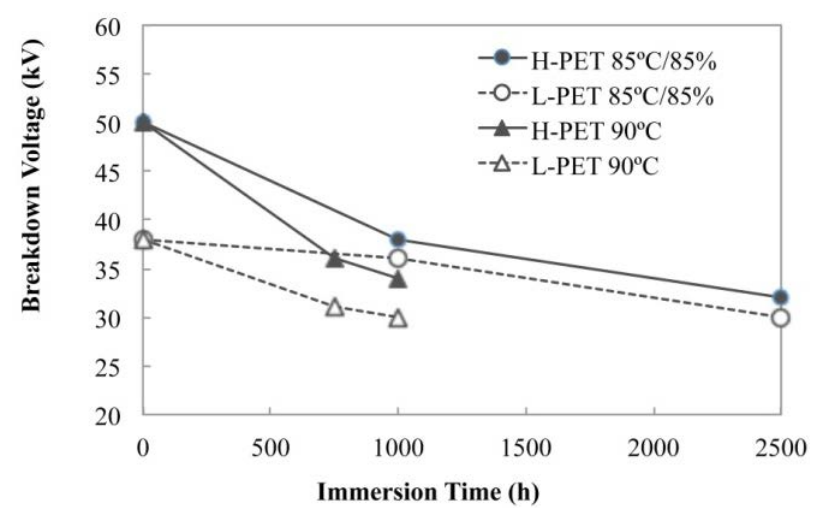

Figure 9. Breakdown voltage of each PET film by the partial discharge test.

measurement. And the cross-sectional images from $\mathrm{H}$ PET and L-PET showed almost same image. However, the mechanical properties and the partial discharge measurement indicated the difference between before and after the acceleration degradation test. In addition, the breakdown voltage test could also detect the degradation of PET films by the acceleration degradation test. Accordingly, it is considered that the partial discharge measurement as a non-destructive analytical technique could use in order to evaluate the degradation of PET film without any damage or cut out for the film.
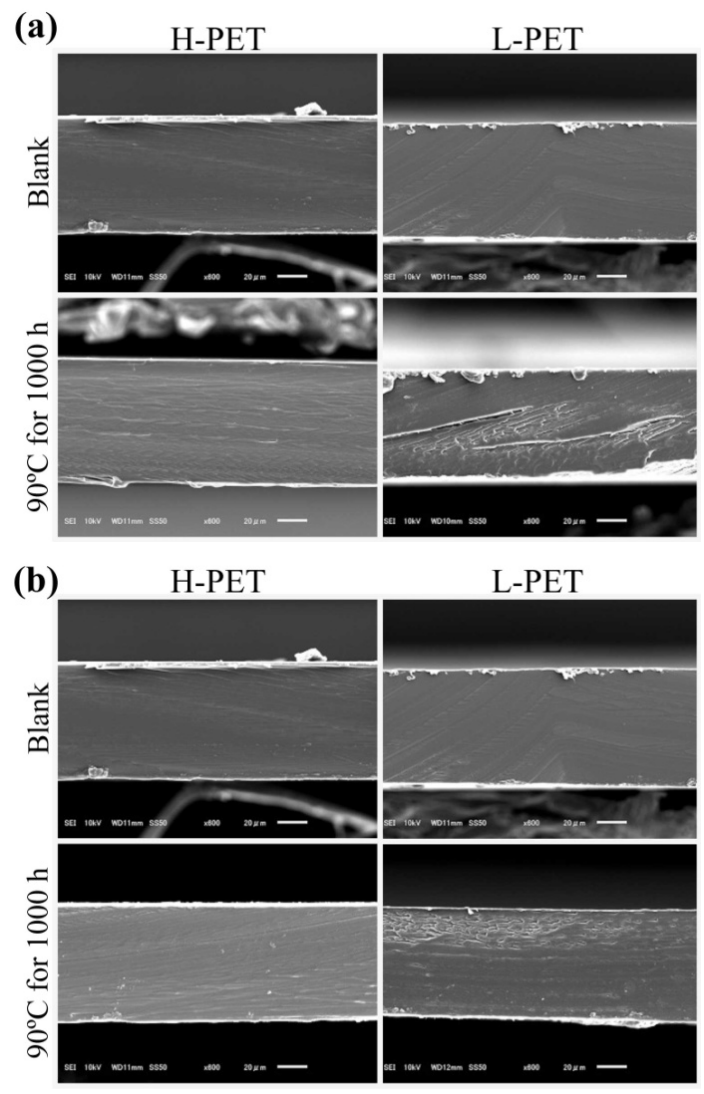

Figure 10. SEM images in cross-sectional direction of $\mathbf{H}$ and L-PET films, (a) before partial discharge measurement, (b) after partial discharge measurement.

\section{Conclusion}

In this research, we try to evaluate the effect of molecular weight for the hydrolysis of PET under the acceleration degradation test. The films were tested under the hot water bath and the constant temperature and humidity chamber. As results, the mechanical properties of PET film were decreased with increasing the acceleration degradation time. In addition, it was found that the partial discharged capacity and the dielectric breakdown strength of PET film indicated the similar tendency with the mechanical properties. Accordingly, the non-destructive analytical technique, i.e. the partial discharge measurement makes it easy to evaluate the degradation of PET film without any damage or cut out for the film.

\section{REFERENCES}

[1] N. Aleshin, H. J. Lee, S. H. Jhang, H. S. Kim, K. Akagi, and Y. W. Park, "Coulomb-Blockade Transport in QuasiOne-Dimensional Polymer Nanofibers,” Physical Review $B$, Vol. 72, No. 15, 2005, Article ID: 153202. http://dx.doi.org/10.1103/PhysRevB.72.153202

[2] E. J. Ra, K. H. An, K. K. Kim, S. Y. Jeong and Y. H. Lee, "Anisotropic Electrical Conductivity of MWCNT/PAN 
Nanofiber Paper," Chemical Physics Letters, Vol. 413, No. 1-3, 2005, pp.188-193.

http://dx.doi.org/10.1016/j.cplett.2005.07.061

[3] X. Lu, Y. Zhao and C. Wang, "Fabrication of PbS Nanoparticles in Polymer-Fiber Matrices by Electrospinning," Advanced Materials, Vol. 17, No. 20, 2005, pp. 24852488. http://dx.doi.org/10.1002/adma.200500196

[4] Y. Hashimoto, Y. Hashimoto, K. Yamada and H. Hamada, "Effect of Heat Sealing Pressure on Mechanical Properties and Molecular Structure at Heat-sealed Parts of Poly(Lactic Acid) Plastic Film," Society of Packaging Science and Technology, Vol. 21, No. 2, 2013, pp. 115-123.

[5] "Nano Porous Films Processing of Polymer Films Based on Localized Surface Plasmon Resonance of Au Nanoparticles,” Journal of Laser Micro/Nanoengineering, Vol. 7, No. 3, 2012, pp. 260-263.

[6] Y. Hashimoto, Y. Hashimoto, K. Yamada and K. Miyata, "Effect of LLDPE Contents on Heat Seal Properties for HDPE/LLDPE Blend Film,” Seikei-Kakou, Vol. 23, No. 11, 2011, pp. 691-697.

[7] T.-Q. Nguyen, R. C. Kwong, M. E. Thompson and B. J. Schwartza, "Improving the Performance of Conjugated Polymer-Based Devices by Control of Interchain Interactions and Polymer Film Morphology," Applied Physics Letters, Vol. 76, 2000, pp. 2454-2456. http://dx.doi.org/10.1063/1.126374

[8] S. Thumsorn, K. Yamada, Y. W. Leong and H. Hamada, "Development of Cockleshell-Derived $\mathrm{CaCO}_{3}$ for Flame Retardancy of Recycled PET/Recycled PP Blend,” Materials Sciences and Applications, Vol. 2, No. 2, 2011, pp. 59-69. http://dx.doi.org/10.4236/msa.2011.22009

[9] N. Kunimune, K. Yamada, Y. W. Leong, S. Thumsorn and H. Hamada, "Influence of the Reactive Processing of Recycled Poly(ethylene terephthalate)/Poly(ethylene-coglycidyl methacrylate) Blends,” Journal of Applied Polymer Science, Vol. 120, No. 1, 2011, pp. 50-55. http://dx.doi.org/10.1002/app.32836

[10] S. Thumsorn, K. Yamada, Y. W. Leong and H. Hamada, "Effect of Pellet Size and Compatibilization on Thermal Decomposition Kinetic of Recycled Polyethylene Terephthalate/Recycled Polypropylene Blend," Journal of Applied Polymer Science, Vol. 124, No. 2, 2012, pp. 1605-1613. http://dx.doi.org/10.1002/app.35166

[11] S. Thumsorn, K. Yamada, Y. W. Leong and H. Hamada, "Thermal Decomposition Kinetic and Flame Retardancy of $\mathrm{CaCO}_{3}$ Filled Recycled Polyethylene Terephthalate/ Recycled Polypropylene Blend,” Journal of Applied Polymer Science, Vol. 127, No. 2, 2013, pp. 1245-1256. http://dx.doi.org/10.1002/app.37673 